\title{
Associative structure of conditioned inhibition produced by inhibitory perceptual learning treatment
}

\author{
Cody W. Polack ${ }^{1} \cdot$ Ralph R. Miller ${ }^{1}$
}

Published online: 12 November 2018

(C) Psychonomic Society, Inc. 2018

\begin{abstract}
Exposure to a set of complex stimuli yields an enhanced ability to discriminate between these stimuli. In previous experimental studies, two distinguishable stimuli, $\mathrm{X}$ and $\mathrm{A}$, were each repeatedly paired with a common Stimulus $\mathrm{B}$ to create compound Stimuli $\mathrm{XB}$ and $\mathrm{AB}$. Prior evidence suggests that unique Features $\mathrm{X}$ and $\mathrm{A}$ form mutually inhibitory associations. This was evidenced by pairing Feature A with a biologically relevant stimulus (i.e., an unconditioned stimulus [US]) and observing that Stimulus $\mathrm{X}$ alone later serves to inhibit anticipatory behaviors for that US. These observations may reflect the mutually inhibitory nature of the two Features $\mathrm{X}$ and $\mathrm{A}$. However, by assessing the influence of $\mathrm{X}$ on behavior that anticipates the US rather than Feature A, these experiments tested inhibition only indirectly. In the present experiments, a more direct measure of inhibition is proposed and tested with rats. We found evidence of retardation and negative summation of associations between unique Features $\mathrm{X}$ and $\mathrm{A}$ in their capacity to serve as competing cues during overshadowing treatments. Stimulus $\mathrm{X}$ was less susceptible to overshadowing by $\mathrm{A}$ (which is indicative of retardation of the establishment of an $\mathrm{X}-\mathrm{A}$ within-compound association) and was able to suppress overshadowing by $\mathrm{A}$ of another stimulus $(\mathrm{Y})$ when $\mathrm{X}$ was presented with $\mathrm{Y}$ at test (which is indicative of negative summation of the representation of $\mathrm{A}$ by $\mathrm{X}$ ). Thus, $\mathrm{XB} / \mathrm{AB}$ trials were seen to establish an inhibitory relationship between $\mathrm{X}$ and $\mathrm{A}$.
\end{abstract}

Keywords Inhibitory perceptual learning $\cdot$ Inhibition between cues $\cdot$ Within-compound inhibition

Animals' experience with seemingly similar yet subtly distinctive stimuli can facilitate their ability to discriminate among them. This perceptual learning effect is thought to be involved in many fine discriminations such as those made by an expert wine taster identifying unique qualities among highly similar wines. Commonly, such effects were viewed as a change in how those preexposed stimuli were now perceived, in that the organism might attend more carefully to the distinctive features and habituate to those that are shared (e.g., Gibson, 1969; Gibson \& Walk, 1956). Alternatively or additionally, these distinctive features may develop inhibitory associations that can aid in differentiating between similar features. Mitchell and Hall (2014) summarized the state of support for each of these mechanisms, referred to as salience modulation and associative inhibition, respectively. Here, we do not seek to identify a conclusive determinant of perceptual

Ralph R. Miller

rmiller@binghamton.edu

1 Department of Psychology, State University of New York at Binghamton, Binghamton, NY 13902-6000, USA learning in general. Instead, we focus on creating a novel assessment of associative inhibition in perceptual learning, but do not set out to categorically reject salience modulation.

Procedurally, inhibitory perceptual learning is often modeled using compounds of individual stimuli that can be combined to create a pair of compounds that share a common feature and also each contains a unique feature (e.g., compounds $\mathrm{XB}$ and $\mathrm{AB}$ ). The present set of experiments addresses the associative structure and measurement of inhibition produced by perceptual learning procedures (i.e., many interspersed presentations of $\mathrm{XB}$ and $\mathrm{AB}$ ). A challenge in assessing possible inhibition between $\mathrm{X}$ and $\mathrm{A}$ is that the stimuli themselves necessarily lack motivational properties. This detail distinguishes inhibitory perceptual learning from Pavlovian conditioned inhibition training, which involves inhibitory associations between a conditioned stimulus (CS) and a biologically relevant unconditioned stimulus (US). Measuring inhibition of a US requires an indirect measurement to identify inhibitory learning, resulting from the need to have something present, or expected to be present, in order to have something to inhibit (i.e., summation and retardation tests; Rescorla, 1969). Inhibition is widely regarded as a slave 
process to excitation (Lysle \& Fowler, 1985). In the case of inhibitory perceptual learning, the inhibited stimulus elicits no unconditioned response; consequently, assessment is even more challenging.

Initial reports of inhibitory perceptual learning were supported by pairing stimulus Feature A with a US, and then testing whether stimulus Feature $\mathrm{X}$ inhibited subsequent expectation of that US. At test, X's inhibition with respect to this US is presumed to be mediated by inhibition between Feature $\mathrm{A}$ and Feature X. A more direct assessment for inhibition of the representation of Feature $\mathrm{A}$, as opposed to direct inhibition of the representation of the US without mediation by A at the time of test, is needed to address the ambiguity regarding whether this perceptual learning paradigm generates inhibition between conditioned stimuli (i.e., $\mathrm{X}$ and $\mathrm{A}$ ), or between X and the US. Dwyer, Bennet, and Mackintosh (2001; see also, Dwyer \& Mackintosh, 2002) and even Espinet, Iraola, Bennett, and Mackintosh (1995) noted that assessing inhibition between unique Features $\mathrm{X}$ and $\mathrm{A}$ by showing that $\mathrm{X}$ also inhibits activation of the representation of the US through an A-US association is a highly indirect measure of inhibition between neutral stimuli. However, the mechanism proposed to explain why inhibition between $\mathrm{X}$ and $\mathrm{A}$ would cause $\mathrm{X}$ to also inhibit the representation of a US that is associated with Stimulus A assumes that the inhibitory performance with respect to the US should covary with the inhibitory learning about A. For example, in the McLaren and Mackintosh (2000) model, the inhibition of Stimulus A by X negatively activates the US associated with A, resulting in the observed inhibition of behavior anticipatory of the US. That is, inhibition of the representation of the US is an indirect effect caused by inhibition of A. Here we assess the validity of this assumption by attempting to dissociate inhibition of a putative comparator stimulus (e.g., Stimulus A) from inhibition of the US.

Dwyer et al. (2001, Dwyer \& Mackintosh, 2002) cleverly addressed this ambiguity regarding the nature of inhibitory perceptual learning by manipulating the motivational value of Stimulus A per se, rather than pairing A with a biologically relevant US (see also Espinet, Artigas, \& Balleine, 2008). This was accomplished by giving compounds of flavored solutions in which Stimulus A (saline) was an element. They then used sodium depletion through injection of formaldehyde, which increases consumption of saline solution (Fudim, 1978) to increase the motivational value of Stimulus $\mathrm{A}$ after the $\mathrm{XB} /$ $\mathrm{AB}$ pretraining trials. In this case, the presence of the Stimulus $\mathrm{X}$ flavor was shown to directly inhibit activation of the representation of Stimulus A because Stimulus A had motivational value. While Dwyer and colleagues' findings suggest that the relationship between $\mathrm{X}$ and A was inhibitory in their paradigm, it does raise the question of whether their Stimulus A could be considered a neutral stimulus, given it had latent motivational properties that could be expressed given subsequent sodium depletion. Thus, Dwyer and colleagues' preparation might be viewed as being more similar to a conventional Pavlovian conditioned inhibition paradigm than to an inhibitory perceptual learning paradigm. Seemingly, the mechanisms involved in the two paradigms are similar. However, to make a more convincing case that inhibitory associations are formed between neutral stimuli as a result of $\mathrm{XB} / \mathrm{AB}$ treatment, in the present series, we explore alternative methods of assessing inhibition between $\mathrm{X}$ and $\mathrm{A}$.

The sodium paradigm for assessing inhibition between neutral Stimuli $\mathrm{A}$ and $\mathrm{X}$ assumes that sodium qualifies as a neutral stimulus during training because sodium presumably has no motivational properties at that time. However, sodium's motivational neutrality depends on the state of the organism. This view assumes that the state of the organism during training alone determines what is learned (an acquisition-focused perspective) and ignores the possibility that the state of the organism at the moment of testing could affect the representation and expression of what had been previously learned (a performance-focused perspective; see Robinson \& Berridge, 2013). To address this concern, we used a new method for assessing the associative structure of within-compound associations after many inhibitory learning perceptual trials. The objective was to differentiate inhibition of US representations from inhibition of CS representations. Using this method, evidence of inhibition of the withincompound association would be observed as a corresponding increase in conditioned fear responding. If this distinction could be made, it would facilitate tests of inhibition between conditioned stimuli that are analogous to Rescorla's (1969) retardation (the present Experiment 1) and negative summation (the present Experiment 2) tests, but avoid the potential confound of inhibition of the US representation. Toward this end, we looked to cue competition preparations, specifically overshadowing, for procedures in which at least in some preparations the strength of the association between competing stimuli has been found to be inversely related to conditioned responding to either element alone (e.g., Amundson, Witnauer, Pineño, \& Miller, 2008; for a theoretical accounting of this relationship, see Stout \& Miller, 2007). Importantly, although the procedure that we used here was modeled after Amundson et al. (2008), who were assessing predictions of the comparator hypothesis (Stout \& Miller, 2007), the present research was centrally intended to examine the associative structure of inhibitory perceptual learning rather than serve as another test of the comparator hypothesis. Hence, we devote little space presently to the issue of whether other models of learning would predict the dependence of overshadowing on a within-compound association in this specific procedure. Rather, Amundson et al.'s empirical finding was simply used as a research probe.

Polack and Miller (2018) recently made a case for the application of comparator theory to the Espinet effect in general. In short, there we asserted that the comparator mechanism, 
which relies on mediation of an $\mathrm{A}-\mathrm{X}$ within-compound association through associations with the common element $\mathrm{B}$, accurately describes the development of inhibition between sensory cues. This approach departs from the suggestion that the common element has dampened salience following interspersed Espinet pretraining (e.g., Mondragón \& Murphy, 2010). It is worth noting that Mondragón and Murphy evidenced retarded acquisition between the common element and the US under several conditions to illustrate decreased salience, whereas the comparator account emphasizes the development of associations between the common element and the unique features of each compound throughout pretraining. While the comparator account lacks a mechanism that anticipates changes in cue salience, it makes some of these predictions based on the activation and suppression of activation of the various cues in a comparator process at the moment of testing.

There remain some issues with the role of the withincompound associations with the common stimulus in the comparator approach, as they may not be necessary for maintaining the inhibition observed after inhibitory sensory preconditioning has taken place, and the rules for the operator switch in Stout and Miller's (2007) formalized version of the comparator account may be inadequately defined. Still, Witnauer and Miller (2011) found that in many instances allowing models to scale expected cue competition with the expected strength of the within-compound association between competing cues improves the models' fit. This is true for performancefocused models like the comparator hypothesis as well as acquisition-focused models like Van Hamme and Wasserman (1994). However, acquisition-focused associative models fail to explain part of the results of Experiment 2 because suppression of a competing stimulus at test should only influence future performance, not the degree of competition on that test trial. While the subsequent experiments rely on the finding that within-compound association strength in some preparations including present one is strongly correlated with the observed degree of competition, we will limit the theoretical discussion of why this occurs to avoid redundancy with Polack and Miller (2018).

\section{Experiment 1: Retardation test}

Experiment 1 (see Table 1) was designed to conceptually replicate, now with additional control conditions, Amundson et al.'s (2008) observation with rats that numerous perceptual learning trials (i.e., $\mathrm{XB} / \mathrm{AB}$ ) attenuated subsequent overshadowing of $\mathrm{CS} X$ by $\mathrm{CS} A$. In an overshadowing treatment (e.g., Pavlov, 1927), a target cue $(\mathrm{X})$ is paired with a US in compound with a second cue (A; i.e., AX-US) and ordinarily results in reduced responding to $\mathrm{X}$ relative to $\mathrm{X}$ having been paired alone with the US (i.e., X-US). Critically, Amundson et al. found that $\mathrm{XB} / \mathrm{AB}$ trials prior to overshadowing treatment attenuated overshadowing of $\mathrm{X}$ by $\mathrm{A}$, but $\mathrm{XB} / \mathrm{AC}$ trials did not. Furthermore, they also observed that the attenuated overshadowing was reversed (i.e., restoring overshadowing of $\mathrm{X}$ by $\mathrm{A}$ ) by nonreinforced exposures to the common element $\mathrm{B}$ either before or after the AXUS overshadowing trials. Amundson et al. concluded that, at least in their preparation, overshadowing is directly dependent on the effective strength of the $\mathrm{X}-\mathrm{A}$ association, and $\mathrm{XB} / \mathrm{AB}$ inhibitory perceptual training creates an inhibitory $\mathrm{X}-\mathrm{A}$ association that retards the development of an $X-A$ excitatory association during the overshadowing trials. Amundson et al.'s analysis of the observations summarized above was cast in the framework of the comparator hypothesis (e.g., Stout \& Miller, 2007). In the comparator framework, retarded development of an excitatory $\mathrm{X}-\mathrm{A}$ within-compound association is expected to increase responding because a weak $\mathrm{X}-\mathrm{A}$ within-compound association should result in less indirect activation of the US representation through an $\mathrm{X}-\mathrm{A}-\mathrm{US}$ associative chain. (see Denniston, Savastano, \& Miller, 2001; Stout \& Miller, 2007, for a fuller theoretical account of why overshadowing is a direct function of the $\mathrm{X}-\mathrm{A}$ association). Of course, this logic would also apply to overshadowing of $\mathrm{A}$ by $\mathrm{X}$, if we were to match their salience and look for reciprocal overshadowing. In the present series, we use a more salient cue for CS A to minimize the risk of failing to observe the basic overshadowing effect.

Importantly, Amundson et al. (2008) found that an XB/ AC control treatment administered prior to AX-US overshadowing treatment did not attenuate overshadowing. This seemingly precludes an account of attenuated overshadowing based on $\mathrm{X}$ having differential $\mathrm{X}$-US inhibitory associations across these two conditions (i.e., $\mathrm{XB} / \mathrm{AB}$ vs. $\mathrm{XB} / \mathrm{AC}$ pretraining) because the $\mathrm{AX}-\mathrm{US}$ overshadowing trials were identical for the two conditions. Thus, Amundson et al.'s design constitutes a type of a retardation test for an inhibitory $\mathrm{X}-\mathrm{A}$ association formed during inhibitory perceptual learning treatment. However, their experimental design did not include a control that permitted assessment of the stimulus specificity of their observations for the $\mathrm{XB} / \mathrm{AB}$ pairings. That is, there was no condition that received YC/DC trials followed by AX-US overshadowing trials. Therefore, it is possible that $\mathrm{XB} / \mathrm{AB}$ pretraining leaves $\mathrm{X}$ less apt to be overshadowed by any potential overshadowing cue, not only A. The present experiment conceptually replicates the Amundson et al. experiment, while also adding a condition to control for this possibility.

The critical manipulation of the present experiment occurred during the reinforced overshadowing trials that 
Table 1 Experiment 1 design: Retardation test for within-compound associations

\begin{tabular}{|c|c|c|c|c|c|c|c|}
\hline Group & $\begin{array}{l}\text { Shaping } \\
\text { Days } 1-5\end{array}$ & $\begin{array}{l}\text { Preexposure } \\
\text { Day } 6\end{array}$ & $\begin{array}{l}\text { Pretraining } \\
\text { (alternating days) } \\
\text { Days } 7-18\end{array}$ & $\begin{array}{l}\text { Overshadowing } \\
\text { (one session/day) } \\
\text { Days } 19-20\end{array}$ & $\begin{array}{l}\text { Test X/Y } \\
\text { (expected } \\
\text { results) } \\
\text { Day } 23\end{array}$ & $\begin{array}{l}\text { Test Y/X } \\
\text { (expected } \\
\text { results) } \\
\text { Day } 26\end{array}$ & Explanation of text expectations \\
\hline Ret X-A & \multirow{3}{*}{$\begin{array}{l}\text { Lever-press } \\
\text { training }\end{array}$} & \multirow{3}{*}{$\begin{array}{r}2 \mathrm{X} / 2 \mathrm{Y} / 2 \mathrm{~B} / \\
2 \mathrm{D} / 2 \mathrm{~A} / 2 \mathrm{C}\end{array}$} & \multirow{3}{*}{$\begin{array}{c}(66 \mathrm{XB} / 66 \mathrm{AB}) \\
\& \\
(66 \mathrm{YD} / 66 \mathrm{CD})\end{array}$} & $\begin{array}{l}(2 \mathrm{XA}+/ 18 \mathrm{XA}-) \\
\& \\
(2 \mathrm{YC}+/ 18 \mathrm{YC}-)\end{array}$ & $\mathrm{CR}$ or $\mathrm{Cr}$ & $\mathrm{CR}$ or $\mathrm{Cr}$ & $\begin{array}{l}\text { Retarded } \mathbf{X}-\mathbf{A} \text { (and } Y-\mathbf{C}) \text { causes reduced } \\
\text { overshadowing of } X \text { by } \mathbf{A}(\text { and } Y \text { by } \mathbf{C}) .\end{array}$ \\
\hline OV Ctrl & & & & $\begin{array}{c}(2 \mathrm{XC}+/ 18 \mathrm{XC}-) \\
\quad \& \\
(2 \mathrm{YA}+/ 18 \mathrm{YA}-)\end{array}$ & $\mathrm{cr}$ & $\mathrm{Cr}$ & $\begin{array}{l}\text { Inhibitory } \mathrm{X}-\mathrm{A} \text { (and } \mathrm{Y}-\mathrm{C}) \text { impotent against } \\
\mathrm{X}-\mathrm{C} \text { (and } \mathrm{Y}-\mathbf{A} \text { ) during overshadowing; } \\
\text { strong overshadowing of } \mathrm{X} \text { by } \mathbf{C}\end{array}$ \\
\hline Acquisition & & & & $\begin{array}{c}(2 \mathrm{X}+/ 18 \mathrm{X}-) \\
\& \\
(2 \mathrm{Y}+/ 18 \mathrm{Y}-)\end{array}$ & $\mathrm{CR}$ & $\mathrm{CR}$ & $\begin{array}{l}\text { No competition during excitatory } \\
\text { acquisition }\end{array}$ \\
\hline
\end{tabular}

Note. \#s indicate the total amount of presentations for the subsequent stimuli. $/$ indicates that the trial types are interspersed. Ret $=$ retardation; OV Ctrl = overshadowing control. $\mathrm{X}$ and $\mathrm{Y}=$ soft (i.e., low-salience) clicks and low-frequency tone, counterbalanced; $\mathrm{B}$ and $\mathrm{D}=$ flashing light and house light off, counterbalanced; A \& C = loud (i.e., high-salience) white noise and siren, counterbalanced. + = US. cr, Cr, and CR = conditioned responding: weak, moderate, and strong, respectively

followed inhibitory perceptual pretraining. During the overshadowing phase, subjects in Group Ret X-A were presented with the XA compound stimulus followed by the US, whereas subjects in Group OV Ctrl were presented with the XC stimulus compound followed by the US, and subjects in Group Acquisition were presented with $\mathrm{X}$ alone followed by the US. A comparison of Group OV Ctrl and Group Acquisition allowed for the assessment of the conventional overshadowing effect within this paradigm. Assuming that inhibitory perceptual pretraining makes $\mathrm{X}$ an inhibitor for activation of the representation of $\mathrm{A}$, the pretraining treatment was expected to retard overshadowing of $\mathrm{X}$ by $\mathrm{A}$, which in this preparation has been found by Amundson et al. (2008) to depend directly on an X-A excitatory association. The present experiments closely followed the procedures of Amundson et al., deviating mainly in doubling the number of inhibitory perceptual pretraining trials, which was done with the intent of enhancing any resultant effects of the treatment. Establishment of an X-A excitatory association should be retarded if $X$ and $A$ have an initially inhibitory relationship due to $\mathrm{XB} / \mathrm{AB}$ pretraining, whereas the $\mathrm{X}-\mathrm{C}$ association should have no initial inhibitory relationship. On a test of Stimulus X, we expected overshadowing to be relatively strong (i.e., weak responding to $\mathrm{X}$ ) in Group OV $\mathrm{Ctrl}$ due to the uninhibited $\mathrm{X}-\mathrm{C}$ association, whereas the inhibitory relationship between $\mathrm{X}$ and $\mathrm{A}$ should result in stronger responding (i.e., less overshadowing) to be observed in Group Ret X-A. This observation would indicate that $\mathrm{X}$ is an inhibitor for that particular conditioned stimulus (i.e., A) as opposed to the US. Any acquired inhibition of the US representation by $\mathrm{X}$ should be evident in both Group Ret X-A and Group OV Ctrl. Thus, the present experiment provides an improved retardation test for inhibition between CSs that is dissociable from any possible inhibition of the US representation.

\section{Method}

\section{Subjects}

Subjects were 24 male (219-251 g), experimentally naïve Sprague-Dawley-descended rats purchased from Harlan (Indianapolis, IN). The animals were divided randomly into three experimental groups, Group Ret X-A, Group OV Ctrl, and Group Acquisition $(n \mathrm{~s}=8)$. The animals received continuous access to Purina Lab Chow. Water availability was restricted to $30 \mathrm{~min} /$ day following a progressive deprivation schedule initiated 1 week prior to the start of the study. The animals were individually housed in a vivarium maintained on a 16/8-hr light/dark cycle. Experimental manipulations occurred near the middle portion of the light phase.

\section{Apparatus}

The apparatus consisted of 12 chambers, each measuring $30 \times$ $30 \times 27 \mathrm{~cm}(1 \times \mathrm{w} \times \mathrm{h})$. The side walls of the chamber were made of stainless steel sheet metal, and the front wall, back wall, and ceiling of the chamber were made of clear Plexiglas. The floor was constructed of $0.3 \mathrm{~cm}$ diameter rods, spaced $1.3 \mathrm{~cm}$ center to center. A mild foot shock, $0.5 \mathrm{~s}, 0.6 \mathrm{~mA}$, could be delivered through the grid floor, which served as the unconditioned stimulus. Each chamber was housed in an environmental isolation chest, which was dimly illuminated by a house light (1.12-W, \#1820 incandescent bulb) mounted on the left wall of the experimental chamber. This light could be temporarily turned off which served as a stimulus in this experiment. Each environmental chamber also contained a $100-\mathrm{W}$ bulb, nominal at $120 \mathrm{VAC}$, but driven at $60 \mathrm{VAC}$ that could emit a flashing light (.25 s on, $.25 \mathrm{~s}$ off). The flashing light and the shutting off of the house light served as Stimuli B and $\mathrm{D}$ (the common elements between the two sets of pretraining compounds), counterbalanced within groups. The lever was located on the right side of a wall of each 
chamber. Each chamber was equipped on the same wall as the lever with a liquid dispenser produced by Lafayette Instrument Co., Model 80201, which could deliver 0.04$\mathrm{ml}$ water through the ceiling of a square recess $(3 \times 6 \times 6$ $\mathrm{cm}, 1 \times \mathrm{w} \times \mathrm{h}$ ) and was located to the right side of each lever. The bottom of the square recess was $3 \mathrm{~cm}$ higher than the floor rods of the chamber.

Ventilation fans in each enclosure provided a constant 76dB (C-scale) background noise. Three $45-\Omega$ speakers mounted on the interior right, left, and back side of each environmental chest were used to deliver a complex low frequency tone (500 and $520 \mathrm{~Hz}$ presented simultaneously), a click train $(6 / s)$, or white noise, respectively. The click train and low frequency tone served as stimuli $\mathrm{X}$ and $\mathrm{Y}, 3 \mathrm{~dB}$ above background counterbalanced within groups. The white noise and siren noise served as Stimuli $\mathbf{A}$ and $\mathbf{C}, 15 \mathrm{~dB}$ above background and counterbalanced within groups (boldface here is used to indicate particularly intense stimuli). The inequity in sound intensities was intended to favor overshadowing. All stimulus presentations were $60 \mathrm{~s}$ in duration, with the exception of testing which used a 300 -s presentation of the target.

\section{Procedure}

Shaping On Days 1-5, all rats were shaped to leverpress during 1-hour daily sessions to perform on a VI20-s schedule for 0.04-ml water. On Days 1 and 2, water was delivered on a fixed time 120-s schedule in addition to a continuous reinforcement schedule for lever presses. On Days 1 and 2, a small amount of water was initially placed on the lever to provoke manipulation of the lever. On Day 3, the fixed time scheduled reinforcement was removed, and lever-pressing was continuously reinforced with water delivery. Rats that did not reach a criterion of 50 lever presses during the session received additional hand shaping on that day and those following. On Days 4 and 5, the continuous schedule of reinforcement was replaced with a VI-20-s schedule of reinforcement. Additional sessions were added for rats that failed to meet a minimum leverpressing requirement of 50 responses per hour. The VI-20-s reinforcement schedule was present during the reshaping and test phases of the experiment. During all other phases of the experiment, no water was available, and the lever was retracted to avoid possible pairings of lever-pressing and delivery of any stimulus.

Preexposure To reduce the likelihood of configuring in the later phases of the experiment, all rats received two presentations of Stimulus X, Y, B, D, A, and $\mathbf{C}$ on Day 6. The preexposure session was $90 \mathrm{~min}$ in duration. Stimulus $\mathrm{X}$ presentations occurred 6 and $75 \mathrm{~min}$ into the session, Stimulus Y presentations occurred 12 and $49 \mathrm{~min}$ into the session, Stimulus B presentations occurred 16 and 83 min into the session, Stimulus Z occurred 20 and 44 min into the session, Stimulus A presentations occurred 24 and $58 \mathrm{~min}$ into the session, and Stimulus C presentations occurred 34 and $65 \mathrm{~min}$ into the session.

Inhibitory perceptual pretraining On Days 7-18, animals received exposure to the inhibitory perceptual pretraining compounds. These compounds consisted of interspersed presentations of stimulus compounds $\mathrm{XB}$ and $\mathrm{AB}$, and interspersed presentations of stimulus compounds YD and $\mathrm{CD}$. The different sets of pretraining compounds were presented on alternating days. On Days 7, 9, 11, 13, 15, and 17, all animals were presented with $\mathrm{XB}$ and $\mathrm{AB}$ compounds, whereas on Days 8, $10,12,14,16$, and 18, animals were presented with YD and CD compounds. All rats received 11 presentations of compound $\mathrm{XB}$ (or YD) and 11 presentations of compound $\mathrm{AB}$ (or CD) during each 110-min daily session (mean ITI $=300$ s, range: $120-360 \mathrm{~s}$ ).

Overshadowing treatment On Day 19 and 20, all animals were placed into the experimental chamber for a single, daily, 60-min session. During the Day 19 (or Day 20, counterbalanced within group) session, Group Acquisition received 18 nonreinforced presentations of CS X and two reinforced presentations of X (ITI = $120 \mathrm{~s})$. Reinforced Stimulus $X$ presentations occurred 21.5 and $45.5 \mathrm{~min}$ into the session for all animals. This lean schedule of reinforcement was shown by Polack and Miller (2018) to produce moderate levels of stimulus control on our lever-press suppression scale, thereby avoiding ceiling effects. These two presentations coterminated with a $0.6-\mathrm{mA}, 0.5$-s foot shock. Six nonreinforced presentations were administered before, between, and after the two reinforced presentations because preliminary studies had found that without these nonreinforced trials, insufficient overshadowing was obtained (in Group OV Ctrl) to permit sensitivity to any potential reduction in overshadowing as a result of inhibitory pretraining. This treatment was repeated for Group Acquisition with CS Y on Day 20 (or Day 19). Animals in Group Ret X-A received the same reinforcement schedule on Compound XA during the Day 19 (or Day 20, counterbalanced within group) session and YC during the Day 20 (or Day 19) session, whereas those in Group OV Ctrl experienced the same reinforcement schedule of Compound XC during the Day 19 (or Day 20, counterbalanced with group) session, and YA during Day 20 (or Day 19). Order of training was counterbalanced with respect to the functional role of each stimulus (X vs. Y, and A vs. C).

Reshaping 1 On Days 21 and 22, the levers were inserted into each chamber, and water was delivered to each rat according 
to a VI-20-s schedule of reinforcement. These sessions were implemented to recover baseline rates of lever pressing that may have been disrupted by the treatments.

Test 1 The levers remained inserted into the chambers, and water was delivered according to a VI-20-s schedule of reinforcement. On Day 23, all rats received one 5-min presentation of the click stimulus (i.e., Stimulus $\mathrm{X}$ or $\mathrm{Y}$, counterbalanced within group) in a 22-min session. Responding was collected in 1-min bins throughout the 22min session. Stimulus onset occurred $10 \mathrm{~min}$ into the test session.

Reshaping 2 On Days 24 and 25, all rats received a daily 60min session with uninterrupted access to the lever. This session was implemented to recover baseline rates of leverpressing that may have been disrupted by the treatments or Test 1.

Test 2 The levers remained inserted into the chambers, and water was delivered according to a VI-20-s schedule of reinforcement. On Day 26, all rats received one 5-min presentation of the Stimulus Y or X (opposite cue from Test 1) in a 22min session, counterbalanced within group (confounded with stimulus identity, i.e., the "click" stimulus was tested on Day 23 and the "tone" stimulus was tested on Day 26). Stimulus presentation procedure and data recording were identical to that of Test 1.

\section{Results}

Figure 1 illustrates the lever-press suppression means among the three conditions. The overshadowing treatment (i.e., Group OV Ctrl) appears to have been effective relative to the acquisition control group. Critically, Group Ret X-A did not exhibit as much reduction in conditioned suppression as Group OV Ctrl. Thus, there appears to be support for a retarded X-A association in Group Ret X-A. The subsequent statistical analysis provides support for these inferences.

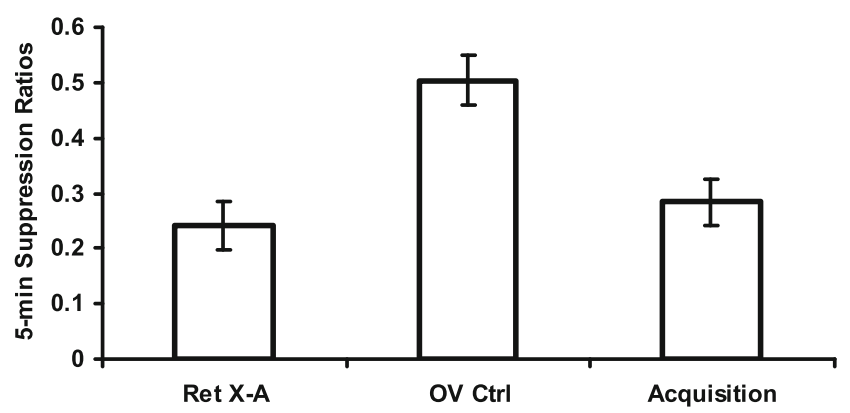

Fig. 1 Group mean suppression ratios for Experiment 1. Error bars represent standard error. Ret $=$ retardation; $\mathrm{OV} \mathrm{Ctrl} \mathrm{=} \mathrm{overshadowing}$ control
A 2 (test day [physical stimulus tested]) $\times 3$ (group) analysis of variance (ANOVA) was conducted on the mean rate of lever presses recorded during the 2 -min period prior to delivery of the test stimulus on Day 23 (clicks test) and Day 26 (tone test). No main effects nor interaction was detected across these pre-CS scores, all $F_{\mathrm{S}}<1$. Two animals (one from Group Ret X-A and one from Group OV) failed to make any responses during this pre-CS period during Day 23, and their data was excluded from the rest of the analysis.

An identical $2 \times 3$ ANOVA was conducted on the suppression ratios calculated by dividing lever-press rates recorded during the 5-min CS presentation by the sum of rates of lever pressing during the pre-CS interval and the CS period (see Fig. 1). There was a main effect of test day, $F(1,19)=13.69, p<0.05$, Cohen's $f=.74,95 \%$ CIs $[.28,1.21]$, with less fear suppression observed on Day 26. There was also a main effect of group, $F(2,19)=$ $10.17, p<0.05$, Cohen's $f=.88$, 95\% CIs [.37, 1.39]. Critically, there was no interaction between the effect of test day and group, $F(2,19)=2.58, p>.10$. As test day was confounded with physical stimulus (clicks vs. tone), and the second test day likely reflected some degree of generalized extinction from the first test day, no further consideration was given to this main effect. Planned comparisons using the ANOVA mean-squared error were conducted to test our predictions regarding the differences across groups. Specifically, the overshadowing treatment proved effective relative to the acquisition group (i.e., $\mathrm{OV}$ Ctrl vs. Acquisition), $F(1,19)=13.09, p<.05$, Cohen's $f$ $=.72,95 \%$ CIs $[.27,1.19]$. Of focal interest, Group Ret $\mathrm{X}-\mathrm{A}$ exhibited attenuated overshadowing relative to Group OV Ctrl, $F(1,19)=17.43, p<.05$, Cohen's $f=$ $.84,95 \%$ CIs $[.36,1.33]$. In fact, the inhibitory perceptual pretraining seems to have prevented any observable effect of overshadowing in Group Ret X-A relative to Group Acquisition, $F<1$. Thus, inhibitory perceptual pretraining attenuated overshadowing between cues that initially were putatively inhibitory. Presumably, this is the result of retarded acquisition of an excitatory within-compound association between $\mathrm{X}$ and $\mathrm{A}$.

\section{Experiment 2: Summation test}

Experiment 2 (see Table 2) was designed to provide a summation test for assessing whether inhibitory perceptual pretraining actually produces an inhibitory within-compound association (i.e., between $\mathrm{X}$ and $\mathrm{A}$ as opposed to $\mathrm{X}$ and the US). A summation test assesses responding to an experimental compound of a transfer conditioned excitor and the putative inhibitor relative to responding to a control compound of the transfer conditioned excitor and a neutral stimulus. Conditioned inhibition is indicated by less responding to the 
Table 2 Experiment 2 design: Negative summation test for within-compound associations

\begin{tabular}{|c|c|c|c|c|c|c|}
\hline Group & $\begin{array}{l}\text { Shaping } \\
\text { Days } 1-5\end{array}$ & $\begin{array}{l}\text { Preexposure } \\
\text { Day } 6\end{array}$ & $\begin{array}{l}\text { Pretraining } \\
\text { (alternating days) } \\
\text { Days } 7-18\end{array}$ & $\begin{array}{l}\text { Overshadowing } \\
\text { (separate sessions) } \\
\text { Days } 19-20\end{array}$ & $\begin{array}{l}\text { Test } \\
\text { Day } 23\end{array}$ & Explanation of text expectations \\
\hline NegSum & \multirow{3}{*}{$\begin{array}{l}\text { Lever-press } \\
\text { training }\end{array}$} & \multirow{3}{*}{$\begin{array}{r}2 \mathrm{X} / 2 \mathrm{Y} / 2 \mathrm{~B} / \\
2 \mathrm{D} / 2 \mathrm{~A} / 2 \mathrm{C}\end{array}$} & \multirow{3}{*}{$\begin{array}{c}(66 \times \mathrm{XB} / 66 \mathrm{AB}) \\
\& \\
(66 \mathrm{YD} / 66 \mathrm{CD})\end{array}$} & \multirow{2}{*}{$\begin{array}{c}(2 \mathrm{fA}+/ 18 \mathrm{fA}-) \\
\quad \& \\
(2 \mathrm{gC}+/ 18 \mathrm{gC}-)\end{array}$} & $\mathrm{Xf}-\mathrm{Cr}$ or $\mathrm{cr}$ & $\begin{array}{l}\text { X Inhibits US/UR \& perhaps A } \\
\text { (attenuated overshadowing) }\end{array}$ \\
\hline Ctrl & & & & & Yf-cr & Y Inhibits US/UR only, not $\mathbf{A}$ \\
\hline Acquisition & & & & $\begin{array}{l}(2 \mathrm{f}+/ 18 \mathrm{f}-) \\
\quad \& \\
(2 \mathrm{gC}+/ 18 \mathrm{gC}-)\end{array}$ & Yf-CR & $\begin{array}{l}\text { Shows 'acquisition' to } f \text { with possible } \\
\text { US/UR inhibition from Y (Equates } \\
\text { effect of } Y \text { with Group Ctrl) }\end{array}$ \\
\hline
\end{tabular}

Note. \#s indicate the total amount of presentations for the subsequent stimuli. / indicates that the trial types are interspersed. NegSum $=$ negative summation; $\mathrm{Ctrl}=$ control. $\mathrm{X}$ and $\mathrm{Y}=$ soft (i.e., low-salience) clicks and low-frequency tone, counterbalanced; $\mathrm{B}$ and $\mathrm{D}=$ flashing light and house light off, counterbalanced; $\mathbf{A}$ and $\mathbf{C}=$ loud (i.e., high-salience) white noise and siren, counterbalanced; $\mathrm{f}$ and $\mathrm{g}$ (transfer excitor) $=$ SonAlert and buzzer, counterbalanced confounded by squad. $+=$ US. $\mathrm{cr}, \mathrm{Cr}$, and $\mathrm{CR}=$ conditioned responding: weak, moderate, and strong, respectively

experimental compound than the control compound. Parallel to the retardation test of Experiment 1, Experiment 2 tested negative summation for activation of a specific CS by examining the resulting influence on overshadowing. Models like SOCR (Stout \& Miller, 2007) and Gallistel and Gibbon (2000) predict that overshadowing depends on the amount of activation of the representation of the overshadowing stimulus at test. Therefore, by presenting an inhibitor for the overshadowing stimulus at test, expression of the overshadowing effect should be reduced. Alternatively stated, presenting an inhibitor for the overshadowing stimulus would be expected to increase responding to the compound test stimulus.

The pretraining treatment used in Experiment 2 was identical to that of Experiment 1. In the subsequent overshadowing phase, $\mathbf{A}$ and $\mathbf{C}$ were used to overshadow two novel, low-salience stimuli, f and g (i.e., fA+ and $\mathrm{gC}+$, with bold letters representing highly salient stimuli). Note that in Group Acquisition, Stimulus f was reinforced alone to provide a comparison to assess our overshadowing treatment. It was necessary to test $\mathrm{f}$ in the presence of Stimulus $\mathrm{Y}$ in both Group Acquisition and Group Ctrl to control for the possibility that $\mathrm{Y}$ was inhibitory for activation of the US, which is a distinct possibility in the typical inhibitory perceptual learning preparation (e.g., Leonard \& Hall, 1999). The critical question here was whether inhibitory perceptual pretraining supports inhibition between the unique cues $\mathrm{X}$ and $\mathrm{A}$ rather than between the target cue $\mathrm{X}$ and the US. Toward this end, for Group NegSum and Group $\mathrm{Ctrl}$, in the Overshadowing phase CS $\mathrm{f}$ was reinforced in compound with CS A, and CS g was reinforced in compound with CS C, whereas for Group Acquisition, CS f was reinforced in the absence of any other cue, and CS $g$ was reinforced in compound with CS C, just like Groups NegSum and Ctrl (see Table 2).

At test, stronger responding to Stimulus $\mathrm{f}$ in the presence of Stimulus X (Group NegSum) than to Stimulus $\mathrm{f}$ in the presence of Stimulus Y ( $\mathrm{Y}$ is an inhibitor for $\mathbf{C}$, not $\mathbf{A}$;
Group Ctrl) would suggest that $\mathrm{X}$ inhibits the specific activation of the representation of Stimulus $\mathbf{A}$. This finding would indicate that the presence of Stimulus $X$ at test suppressed expression of overshadowing of $\mathrm{f}$ by $\mathbf{A}$. If inhibition was for the US representation, $\mathrm{X}$ and $\mathrm{Y}$ should have comparable effects because their treatments with respect to the US were identical. The only difference between the treatments of $\mathrm{X}$ and $\mathrm{Y}$ was whether the cue that they potentially inhibited was a potential overshadower of target CS f (i.e., A) or of irrelevant CS g (i.e., C). The presence of $\mathrm{Y}$ at test in Group Ctrl and Group Acquisition serves to control for the potential for $\mathrm{X}$ in Group NegSum to function as a conditioned inhibitor for the US and additionally controls for external inhibition or stimulus generalization. Thus, this experiment served as a test for negative summation between conditioned Stimuli $\mathrm{X}$ and $\mathrm{A}$, much like Experiment 1 assessed retarded acquisition of an excitatory within-compound association between $\mathrm{X}$ and $\mathrm{A}$. In both cases, conditioned inhibition of $\mathrm{A}$ by $\mathrm{X}$ should have attenuated expression of overshadowing of $X$ by $\mathrm{A}$ in Experiment 1, and of $\mathrm{f}$ by $\mathrm{A}$ in Experiment 2. In both cases, the expected consequence was increased responding at test. Therefore, Experiments 1 and 2 conjointly constitute the first combination of negative summation and retardation tests for conditioned inhibition between cues per se, rather than the US, within an inhibitory perceptual learning preparation.

\section{Method}

\section{Subjects}

Subjects were 48 male (226-256 g), experimentally naïve, Sprague-Dawley-descended rats purchased from Harlan (Indianapolis, IN). The animals were randomly assigned into three experimental groups, Group NegSum, Group OV Ctrl, and Group Acquisition ( $n \mathrm{~s}=16)$. Animal housing was identical to that of Experiment 1. 


\section{Apparatus}

Aside from the additional stimuli noted below, the apparatus and stimuli were identical to that of Experiment 1. Each chamber was fitted with a SonAlert and a buzzer. These stimuli served as overshadowed Stimuli f and g, counterbalanced within groups. These stimuli were $3 \mathrm{~dB}$ (C-scale) above background.

\section{Procedure}

\section{Shaping, preexposure, and inhibitory perceptual pretraining} All three of these phases of treatment were identical to those of Experiment 1.

Overshadowing treatment On Days 19 and 20, all animals were placed into the experimental chamber for a daily 60 min session. On Day 19 (or Day 20, counterbalanced within groups), animals in Groups NegSum and Ctrl received 18 nonreinforced and two reinforced presentations of Compound fA, whereas Group Acquisition received identical treatment, except presentations of Compound fA were replaced with presentations of $\mathrm{f}$ alone. On Day 20 (or Day 19), animals in all three groups received 18 nonreinforced and two reinforced presentations of Compound gC. Each reinforced presentation of a stimulus coterminated with a $0.5-\mathrm{s}, 0.6-\mathrm{mA}$ foot shock. Compound cues onset occurred 21.5 and $45.5 \mathrm{~min}$ into the session. The order of $\mathrm{fA}$ (or $\mathrm{f}$ alone) and $\mathrm{gC}$ training sessions was counterbalanced within groups, but order of sessions was confounded with the physical identities of the stimuli.

Reshaping Prior to reshaping, the levers were inserted into each chamber. Water was delivered according to a VI-20-s schedule of reinforcement. On Days 21 and 22, all rats received a daily 60 -min session in which rats had uninterrupted access to the lever press. These sessions were implemented to recover baseline rates of lever-pressing that may have been interrupted by the treatments.

Test The levers remained inserted into the chambers, and water was delivered according to a VI-20-s schedule of reinforcement. On Day 23, all rats received one 5-min presentation of either the compound Xf (Group NegSum) or the compound Yf (Group Ctrl and Group Acquisition) in a 22-min session. Lever pressing was recorded in 1-min bins throughout the 22min session (including after CS offset). Test stimulus onset occurred 10 min into the session.

\section{Results}

Figure 2 illustrates the lever-press suppression means among the three conditions. Consistent with the findings in Experiment 1, Group Acquisition displayed more conditioned suppression than

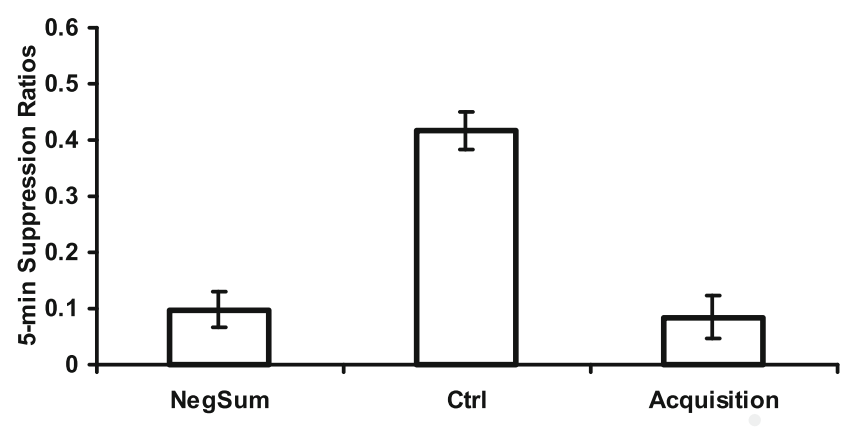

Fig. 2 Group mean suppression ratios for Experiment 2. Error bars represent standard error. NegSum $=$ negative summation; $\mathrm{Ctrl}=$ control

that Group Ctrl. Moreover, Group NegSum exhibited a level of conditioned suppression similar to Group Acquisition, thereby suggesting that cue competition was suppressed in Group NegSum. The presence of stimulus $f$ was apparently sufficient to prevent effective activation of the competing Stimulus A. The statistical analysis below supports these inferences.

One rat (Group NegSum) was removed from the analysis for failing to respond during the pre-CS period. A one-way ANOVA was conducted on the 2-min period immediately preceding the compound test presentation. No reliable differences were observed during this pre-CS period, $F<1$. An identical ANOVA was conducted on the suppression ratios calculated using the rate of lever-pressing during the presentation of the test compound (5-min) divided by the sum of rates of leverpressing over the pre-CS and test presentation. This analysis revealed a reliable difference among the three conditions, $F(2$, $44)=30.08, p<.05$, Cohen's $f=1.10,95 \%$ CIs $[.74,1.46]$.

Planned contrasts were conducted to determine the source of this difference and test specific hypotheses. Critically, less conditioned suppression was obtained in Group Ctrl relative to Group Acquisition, $F(1,44)=47.33, p<.05$, Cohen's $f=$ $.99,95 \%$ CIs $[.64,1.33]$. In other words, overshadowing was obtained with the present parameters. Of central theoretical interest, Group NegSum showed more conditioned suppression than did Group Ctrl, $F(1,44)=42.28, p<.05$, Cohen's $f$ $=.93,95 \%$ CIs $[.60,1.27]$. This indicates that the presence of CS X attenuated expression of overshadowing of CS $\mathrm{f}$, whereas the presence of Stimulus Y did not appreciably attenuate expression of overshadowing of CS $\mathrm{f}$. Thus, the presentation of a stimulus at test that received inhibitory pretraining specifically with overshadowing stimulus A was able to effectively disrupt the effects of the overshadowing stimulus. Any account of overshadowing that relies on limited resources (i.e., expectation of the US or attention to CSs) at the moment of overshadowing training struggles with this observation because the effects of overshadowing training were shown to be determined by the circumstances of testing. Specifically, the overshadowing effect was affected by the presence or absence of a potential inhibitor (X or Y) for the test CS's (i.e., $f$ or $\mathrm{g}$ ) overshadowing stimulus (A or $\mathbf{C}$ ). Notably, this 
inhibition of a specific CS representation ( $\mathbf{A}$ or $\mathbf{C}$ ) is differentiated from any possible inhibition of the biologically relevant US (foot shock) because inhibition was indicated by an increase in the US anticipatory response of disrupted licking. Thus, Experiment 2 provides a successful negative summation test for $\mathrm{XB} / \mathrm{AB}$ inhibitory pretraining producing an inhibitory association between $\mathrm{X}$ and $\mathrm{A}$ that is dissociated from inhibition of the biologically relevant US.

\section{General discussion}

Pretraining consisting of inhibitory perceptual learning treatment (i.e., $\mathrm{XB} / \mathrm{AB}$ ) was shown to attenuate overshadowing in two distinctly different ways. In Experiment 1, the putative inhibitory relationship between two cues retarded the overshadowing effect between these cues provided that they had shared a common stimulus during pretraining. The observed attenuation of cue competition was specific to the condition in which the two cues were putative inhibitors for one another, and not merely inhibitors for overshadowing stimuli in general, the US, or the behavioral response. If inhibitory perceptual learning merely shifts attention to unique cues in a perceptual learning situation, the consequences for subsequent overshadowing should have been similar whether or not the competing cues shared a common element during pretraining. This lends support to the view that pretraining resulted in conditioned inhibition between the cues that shared a common element, and makes implausible the suggestion that a change in attention might have contributed to the observed attenuation in overshadowing. Passage of a Pavlovian conditioned inhibition retardation test might be explained by reduced attention to the putative inhibitor, which could then result in a weaker association of the putative conditioned inhibitor with the US being formed during acquisition. However, in the case of inhibitory perceptual learning treatment, it is less clear why a decrease in attention to the target CS (X in Experiment 1) would occur, and more critically, how such a decrease in attention to the target CS might account for the observed increase in responding to $\mathrm{X}$ (i.e., a reduction in overshadowing). However, one might speculate that inhibitory perceptual learning treatment increased attention to X, which is consistent with the observed reduced overshadowing. But in this case, the reduction in overshadowing should have been observed with overshadowing by C (i.e., Group OV Ctrl) as well as A (i.e., Group Ret X-A), which is contrary to the results of Experiment 1. Thus, the results of Experiment 1 appear to be explicable only in terms of an $\mathrm{X}-\mathrm{A}$ inhibitory association, not an $\mathrm{X}-\mathrm{US}$ association.

Experiment 2 provided a negative summation test for inhibition between the unique elements of an inhibitory perceptual learning preparation. Reduced overshadowing was observed if, and only if, the overshadowed cue was tested in the presence of a putative inhibitor of the overshadowing cue for that particular overshadowed cue. That is, overshadowing was attenuated only when testing occurred in the presence of the putative inhibitor for the overshadowing stimulus that was specific to the overshadowed cue being tested. As in Experiment 1, we observed inhibition for a specific CS, the CS that was the overshadowing cue for the overshadowed cue being tested. By suppressing activation of the overshadowing cue representation, responding to the overshadowed cue was increased. Critically, Experiments 1 and 2 both found an inverse relationship between inhibitory learning between two conditioned stimuli and conditioned responding.

A fundamental assumption in the present research is the importance of within-compound associations and the strength of these associations in producing the behavioral phenomenon of overshadowing, which is perhaps the most straightforward example of cue competition. This assumption is captured in the conceptualization of cue competition provided by the comparator hypothesis (formalized as SOCR; Stout \& Miller, 2007). A recent modification to the Rescorla and Wagner (R-W; 1972) model, or more accurately, modification of Van Hamme and Wasserman's (1994) modification of R-W (also see Dickinson \& Burke, 1996) has also emphasized the dependence of cue competition on the strength of the withincompound association between competing cues (Witnauer \& Miller, 2011). One distinction between the comparator hypothesis (SOCR) and modified R-W approaches is the distinction between when cue competition actually occurs. SOCR assumes the activation of competing stimuli at the moment of testing determines competitive processes, whereas, modifications to R-W rely on the assumption that cues compete during training. Experiment 2 provides rather clear support for the perspective that, at least with the present preparation and parameters, competitive processing occurs at test and is determined by the potential of the subject to reactivate the representation of the relevant competing stimulus. Of course, we must be cautious with this assumption because, although a number of predictions concerning cues (and outcomes) that are trained in compound have been empirically confirmed in other reports as well as the present experiments that suggest a central role for within-compound associations (i.e., counteraction effects; e.g., McConnell, Miguez, \& Miller, 2013), problems have been identified with positing a ubiquitous rule concerning a direct relationship between the strength of within-compound associations and cue competition (e.g., Melchers, Lachnit, \& Shanks, 2006; also see Connor, Lolordo, \& Trappenberg, 2014).

Inhibitory perceptual learning is challenging to assess because the putative association between the unique elements does not lend itself to direct observation. Early investigations 
inferred inhibition among the two elements by assessing conditioned inhibition with respect to a US that had been paired with one of the elements (e.g., Espinet et al., 1995). Accounts of Espinet et al.'s initial findings, such as McLaren and Mackintosh (2000), often relied on generalizing the observed inhibition of the US back to a supposed inhibition of the element that had been paired with the US. The US and the cue paired with it were assumed to covary in tandem in their [inhibitory] relationship with the other unique element. The present data present somewhat of a challenge to this view because the control conditions specifically precluded the observed group differences from arising from generalization of inhibition. These observations are consistent with SOCR's prediction that conditioned suppression should increase as activation of the competing cue decreases, a negative covariation. These experiments were motivated by a comparator hypothesis account of inhibitory perceptual learning, and the observed impact of Espinet pretraining on cue competition appears to be congruent with that account. Another explanation of the present observations might be found in the form of a hybrid elemental and configural model such as McLaren, Forrest, and McLaren (2012) proposed. But, as those authors point out, it becomes difficult to anticipate how such hybrid mechanisms will interact. While inhibition clearly did not generalize from the target cue to US in the present preparation, we acknowledge that with other parameters such generalization might occur. Additionally, we acknowledge that the present evidence of inhibition between initially neutral cues may have been driven by some mechanism other than those posited by the comparator hypothesis.

The primary purpose of the present research was to provide summation and retardation tests for any potential inhibitory relationship between the unique elements in an $\mathrm{XB} / \mathrm{AB}$ inhibitory perceptual learning preparation using procedures that paralleled as closely as possible traditional assessments of Pavlovian conditioned inhibition, yet precluded the possibility of an X-US inhibitory relationship in accounting for the observed behavior. In so doing, we sought associative mechanisms that appear to apply in Pavlovian conditioned inhibition preparations to an inhibitory perceptual learning paradigm. In this sense, we were implicitly testing the assumption that associations between neutral stimuli (two conditioned stimuli) are governed by similar, if not the same, principles that obtain between a CS and a US.

Acknowledgements This research was supported in part by NIMH Award MH033881. We are grateful to Sarah R. O'Hara for her help in collecting the data and to Alaina S. Berruti, Crystal Casado, Zekiel Factor, Jeff J. Joseph, Audrey Li, Patty Li, Tori Pena, and Anna Tsvetkov for their comments on a preliminary version of this manuscript. The data reported here are available from either author.
Publisher's Note Springer Nature remains neutral with regard to jurisdic-

\section{References}

Amundson, J. C., Witnauer, J. E., Pineño, O., \& Miller, R. R. (2008). An inhibitory within-compound association attenuates overshadowing. Journal of Experimental Psychology: Animal Behavior Processes, 34, 133-143. https://doi.org/10.1037/0097-7403.34.1.133

Connor, P. C., Lolordo, V. M., \& Trappenberg, T. P. (2014). An elemental model of retrospective revaluation without within-compound associations. Learning \& Behavior, 42, 22-38. https://doi.org/10.3758/ s13420-013-0112-z

Denniston, J. C., Savastano, H. I., \& Miller, R. R. (2001). The extended comparator hypothesis: Learning by contiguity, responding by relative strength. In R.R. Mowrer \& S.B. Klein (Eds.), Handbook of contemporary learning theories (pp. 65-117). Hillsdale, NJ: Erlbaum

Dickinson, A., \& Burke, J. (1996). Within-compound associations mediate the retrospective revaluation of causality judgements. Quarterly Journal of Experimental Psychology, 49B, 60-80. https://doi.org/10. 1080/713932614

Dwyer, D. M., Bennett, C. H., \& Mackintosh, N. J. (2001). Evidence for inhibitory associations between the unique elements of two compound flavours. Quarterly Journal of Experimental Psychology, 54B, 97-107. https://doi.org/10.1080/713932748

Dwyer, D. M., \& Mackintosh, N. J. (2002). Alternating exposure to two compound flavors creates inhibitory associations between their unique features. Animal Learning \& Behavior, 30, 201-207. https://doi.org/10.3758/BF03192829

Espinet, A., Artigas, A. A., \& Balleine, B. W. (2008). Inhibitory sensory preconditioning detected with a sodium depletion procedure. Quarterly Journal of Experimental Psychology, 61, 240-247. https://doi.org/10.1080/17470210601154594

Espinet, A., Iraola, J. A., Bennett, C. H., \& Mackintosh, N. J. (1995). Inhibitory associations between neutral stimuli in flavor-aversion conditioning. Animal Learning \& Behavior, 23, 361-368. https:// doi.org/10.3758/BF03198935

Fudim, O. K. (1978). Sensory preconditioning of flavors with a formalininduced sodium need. Journal of Experimental Psychology: Animal Behavior Processes, 4, 276-285. https://doi.org/10.1037/2F00977403.4.3.276

Gallistel, C. R., \& Gibbon, J. (2000). Time, rate and conditioning. Psychological Review, 100, 289-344. https://doi.org/10.1037/0033295X.107.2.289

Gibson, E. J. (1969). Principles of perceptual learning and development. New York, NY: Appleton-Century-Crofts.

Gibson, E. J., \& Walk, R. D. (1956). The effect of prolonged exposure to visually presented patterns on learning to discriminate them. Journal of Comparative and Physiological Psychology, 49, 239-242. https:// doi.org/10.1037/h0042523

Leonard, S., \& Hall, G. (1999). Representation-mediated inhibitory learning in the conditioned-suppression procedure. Quarterly Journal of Experimental Psychology, 52B, 145-158. https://doi.org/10.1080/ 713932701

Lysle, D. T., \& Fowler, H. (1985). Inhibition as a "slave" process: Deactivation of conditioned inhibition through extinction of conditioned excitation. Journal of Experimental Psychology: Animal Behavior Processes, 11, 71. https://doi.org/10.1016/0023-9690(88) 90008-2

McLaren, I. P., Forrest, C. L., \& McLaren, R. P. (2012). Elemental representation and configural mappings: Combining elemental and configural theories of associative learning. Learning \& Behavior, 40, 320-333. https://doi.org/10.3758/s13420-012-0079-1 
McLaren, I. P. L., \& Mackintosh, N. J. (2000). An elemental model of associative learning: I. Latent inhibition and perceptual learning. Animal Learning \& Behavior, 28, 211-246. https://doi.org/10. 3758/BF03200258

Melchers, K., Lachnit, H., \& Shanks, D. R. (2006). The comparator theory fails to account for the selective role of within-compound associations in cue-selection effects. Experimental Psychology, 53, 316-320. https://doi.org/10.1027/1618-3169.53.4.316

McConnell, B. L., Miguez G., \& Miller R. R. (2013). Extinction with multiple excitors. Learning \& Behavior, 41, 119-137. https://doi. org/10.3758/s13420-012-0090-6

Mitchell, C., \& Hall, G. (2014). Can theories of animal discrimination explain perceptual learning in humans? Psychological Bulletin, 140, 283-307. https://doi.org/10.1037/a0032765

Mondragón, E., \& Murphy, R. A. (2010). Perceptual learning in an appetitive Pavlovian procedure: Analysis of the effectiveness of the common element. Behavioural Processes, 83, 247-256. https:// doi.org/10.1016/j.beproc.2009.12.007

Pavlov I. P. (1927). Conditioned reflexes (G. V. Anrep, Trans.). London, UK: Oxford University Press.

Polack, C. W., \& Miller, R. R. (2018). Inhibition and mediated activation between conditioned stimuli: Parallels between perceptual learning and associative conditioning. Journal of Experimental Psychology:
Animal Learning and Cognition, 44, 194-208. https://doi.org/10. 1037/xan0000166

Rescorla, R. A. (1969). Pavlovian conditioned inhibition. Psychological Bulletin, 72, 77-94. https://doi.org/10.1037/h0027760

Rescorla, R. A., \& Wagner, A. R. (1972). A theory of Pavlovian conditioning: Variations in the effective- ness of reinforcement and nonreinforcement. In A. H. Black \& W. F. Prokasy (Eds.), Classical conditioning II: Current research and theory (pp. 64-99). New York, NY: Appleton-Century-Crofts.

Robinson, M. J., \& Berridge, K. C. (2013). Instant transformation of learned repulsion into motivational "wanting". Current Biology, 23, 1-8. https://doi.org/10.1016/j.cub.2013.01.016

Stout, S. C., \& Miller, R. R. (2007). Sometimes competing retrieval (SOCR): A formalization of the extended comparator hypothesis. Psychological Review, 114, 759-783. https://doi.org/10.1037/0033295X.114.3.759

Van Hamme, L. J., \& Wasserman, E. A. (1994). Cue competition in causality judgments: The role of nonpresentation of compound stimulus elements. Learning and Motivation, 25, 127-151. https://doi. org/10.1006/lmot.1994.1008

Witnauer, J. E., \& Miller, R. R. (2011). The role of within-compound associations in learning about absent cues. Learning \& Behavior, 39, 146-162. https://doi.org/10.3758/s13420-010-0013-3 